\title{
Designing for culturally-diverse communities. The role of collaborative, interdisciplinary design-led research
}

\author{
Jacqueline Mclntosh, Bruno Marques \\ Victoria University of Wellington, New Zealand \\ School of Architecture \\ jacqueline.mcintosh@vuw.ac.nz | bruno.marques@vuw.ac.nz
}

\begin{abstract}
Successful design for culturally-diverse communities hinges on a nuanced understanding of the cultural environment; building trusting relationships and fostering a respectful approach to community. This paper discusses the application of design-led research with a participatory mind-set and maintains that while a collaborative, interdisciplinary participatory design process is essential, a design-led research approach is particularly valuable. Blurring the boundaries between disciplines brings the users to the forefront of design as active cocreators, sharing ideas, tools and methods. It examines two projects - a Tokelau / Pasifika cultural museum exhibition involving museum curators, architects, interior designers, photographers and local community members; and a Māori landscape regeneration project in the Wairarapa region of Wellington - wherein the designers (in this case the students) took the role of facilitator rather than providing a hierarchical and potentially adversarial approach to community design decision-making. The research project was framed around three critical stages: design analysis (holistic context), design exploration and testing (exploring design scenarios), and design synthesis (agreed plan or direction). It finds that participatory design when performed correctly can increase the capacity for community engagement; provide substantial benefits to the design outcomes; and beneficially exploit the process of design-led research. In addition to the community benefits, this interdisciplinary and collaborative research process can create new opportunities for architectural design education as it educates students as world citizens. As such it has the potential to transform architectural practice.
\end{abstract}

Keywords: participatory design, design-led research, interdisciplinary research, collaborative research, Māori Pasifika.

\section{To cite this article:}

McIntosh, J., Marques, B. (2017). Interdisciplinary, collaborative design-led research for culturallydiverse communities. The Journal of Public Space, 2(3), Special Issue, 2I-30, DOI:

10.5204/jps.v2i3. 109

This article has been peer-reviewed and accepted for publication in The Journal of Public Space. Please see the Editorial Policies under the 'About' section of the journal website for further information.

This work is licensed under a Creative Commons Attribution - Non Commercial 4.0 International License https://creativecommons.org/licenses/by-nc/4.0/ 


\section{Introduction}

The nature and characteristics of design-led research in academia are in a state of flux. The research model where the prevailing culture is 'experts' designing for people, that has typically led practice, has had a long and extensive history in academia. However, more recently a design-led perspective has come into focus with a common goal of driving, inspiring and informing the design process'. In both academia and practice, this perspective shares a history of 'expert' designers creating for people and in both approaches, the end users are seen as reactive informers ${ }^{2}$. This paper explores an alternative view where the users are seen as partners, or active co-creators in the design process. To date, there has been broad diversity in practices and behaviours in this regard. Some researchers/designers essentially engage in symbolic activities or 'window dressing' to create an impression of commitment to community development, while others display a genuine commitment by expending substantial resources that go well beyond any legal obligations ${ }^{3}$. This paper considers both perspectives as it discusses the application of design-led research through a collaborative and interdisciplinary participatory design-led process, which in turn forms an essential interface between teaching and practice. More specifically, it discusses a series of interdisciplinary activities that were the result of collaboration between various community groups and the School of Architecture at Victoria University of Wellington, where participatory design methods were employed in the design and development of community facilities and environments. Two interdisciplinary and collaborative student projects were considered within this paper: a Tokelau / Pasifika cultural museum exhibition at the Pataka Art + Museum in Porirua, and a Māori landscape regeneration project in the Wairarapa exhibited in a local community hall in Featherston.

- Tokelau: Then Now, Now Then involved 15 interdisciplinary Victoria University of Wellington students (architecture, interior architecture and landscape architecture) working collaboratively and closely with museum curators, interior designers, photographers, anthropologists, architects and local members of the Tokelau community based in Porirua, New Zealand to design a "cultural museum" representing Tokelau customs, interactions and design-based rituals.

- Akoranga: Wairarapa Moana involved 20 Victoria University of Wellington students of landscape architecture working collaboratively with the Greater Wellington Regional Council, South Wairarapa District Council and members of the local Māori iwi Ngāti Kahungunu ki Wairarapa based in the Wairarapa, New Zealand to design sustainable and culturally sensitive solutions to the flooding of the Ruamahanga and Tauherenikau Rivers and Lake Wairarapa.

Both groups of students attended a number of workshops where they consulted with prominent members of the local Pasifika and Māori communities respectively. The two final exhibitions allowed critical reflection on the results in the context of community engagement.

\footnotetext{
' Kirsikka Vaajakallio and T. Mattelmaki. "Collaborative Design Exploration: Envisioning Future Practices with Make Tools" Proceedings of the 2007 Conference on Designing Pleasurable Products and Interfaces, 223-238, New York ACM Press, 2007.

2 Liz Sanders, “Design Research in 2006”. Design Research. Quarterly I, n. I (2006) Design Research Society.

${ }^{3}$ Ciaran O'Faircheallaigh, "Aborigines, Mining Companies and the State in Contemporary Australia: A New Political Economy or "business as Usual'?" Australian Journal of Political Science 4I, n. I (2006): I-22. p. 6.
} 
The motivation for a participatory process came from the lack of traditional research from which to base design for Māori and Pasifika communities. To understand the complexly structured world of diverse societies, the researcher must understand that people are far different in nature from data and processes. People have different and conflicting objectives, perceptions, and attitudes; and they often change over time. Good design solutions are rarely clear, and winning the agreement of all interested parties is quite difficult. An iterative process involving design researchers with users and students acting together on a particular series of activities, including problem diagnosis, action intervention, and reflective learning, allows the researcher to gain feedback from the experience, modify the design as a result of the feedback and try it again. Each iteration of the process adds to the framework and informs the eventual design.

\section{Users as active co-creators: developing collaborative relationships}

The process for ensuring community members were able to participate in a rich and empowering design process has been summarised under the following four sub-headings:

I) Understanding - of place

2) Relationships - building upon trust

3) Respect - sensitive facilitation

4) Participation - sharing of knowledge

Understanding: A participatory design process always commences prior to first contact. With both communities, design practitioners had to develop a holistic understanding of the project environment (social, ecological, economic and political), and the history of events and beliefs that shaped the current situation. In addition, they required knowledge of the degree to which there was capacity within the community. For the Tokelau community, this involved a broad multi-disciplinary review of the literature, including ethnographic, ecological, medical, economic, sociological, anthropological and political literature. A detailed inventory of all community members, their interests, their affiliations and the areas in which they wished to contribute as then collected. For the Wairarapa project, students worked with the local iwi to understand their cultural protocols, tribal affiliations and their relationship to the wider environment and community.

Relationships: During the relationship-building phase, the creation of trust was imperative for opening the channels of communication between members of the engagement team and the residents, other stakeholders, and project participants. For the Tokelau community, this involved formal introductions through the former mayor and city councillors following with many hours of meetings, social gatherings and events which facilitated discussion. The relationship developed over a three year period and eventually involved numerous student projects. For the Wairarapa project, the process was initiated by an invitation from community elders for a get-together, wherein the community defined its own design priorities by identifying projects with strong spiritual or cultural meaning. This relationship also developed over a three year period and involved many hours of active listening, social interaction and discussion. To be sustainable long-term, students and designers must undertake relationship-building activities over numerous years within the communities, engaging with a personal style of interaction to gain 
appropriate levels of trust and respect. From these experiences, we have come to realise the importance of meeting people on their own terms, developing informal meeting opportunities and building relationships by listening 'one-on-one'.

Respect: The notion of storytelling is an integral part of Māori and Pasifika cultures and had to be acknowledged for both the Tokelau and Wairarapa relationships to be successful. The sharing of food was also an important and on-going activity for establishing cultural respect.

Participation: Techniques for optimal participation involved working with established community and stakeholder groups, rather than imposing purpose-built committees. It quickly became evident in all projects undertaken to date that active people within smaller communities were already stretched, often overworked and were also involved in the delivery of many other menial community tasks. Finding ways to support local champions can often be the beginnings of allowing space for the community to develop or grow in new directions.

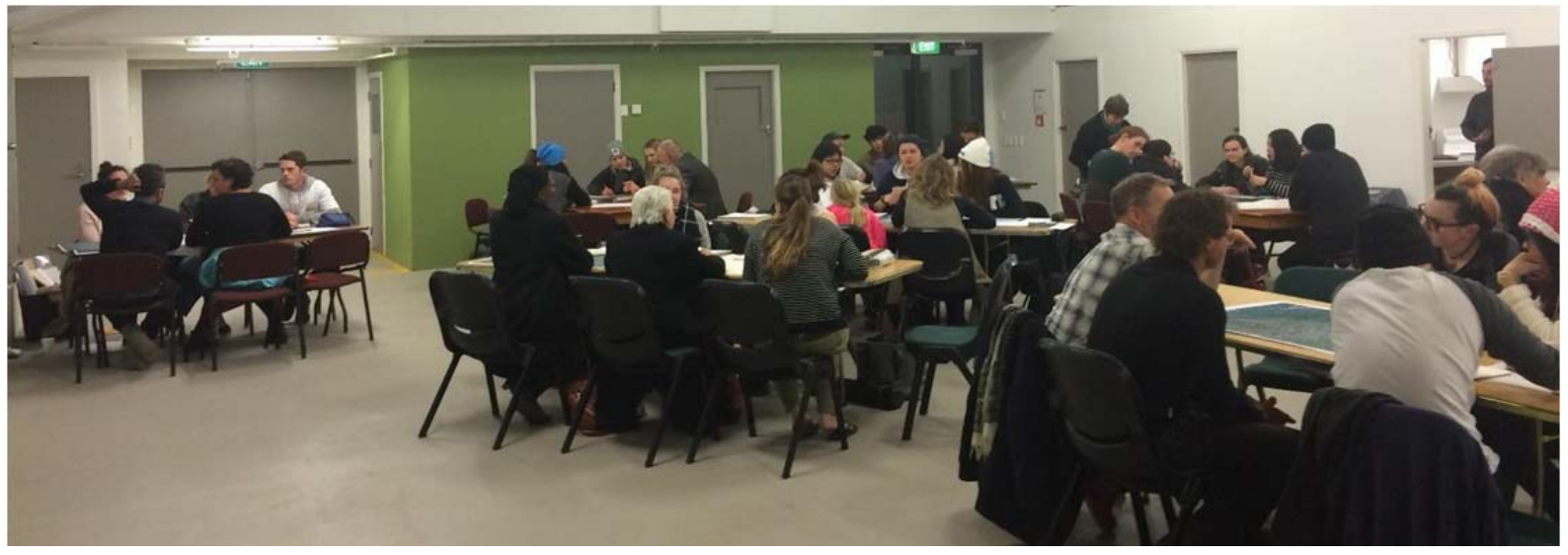

Figure I: Akoranga: Wairarapa Moana project: Students meeting with local community members.

Introducing students to the local Tokelau and Māori communities facilitated an exchange of cultural information, which enabled the communities to design with-and-through the students. The connection allowed students to work in Māori and Pasifika traditional models of engagement which respect to life experience over abstract theory. While this type of connection is only superficial at best in a highly complex cultural context, it can assist students going forward as future professionals, through an awareness of the existence of these often-hidden values. From the university's perspective the relationship provided the means to train its students as future professionals of the built environment by working with real clients, while also preparing them to be socially responsible world citizens.

Educationally, these interdisciplinary and collaborative approaches are grounded in critical pedagogy, ${ }^{4}$ social learning theories, ${ }^{67}$ and constructive developmental theories. ${ }^{8} 9$

\footnotetext{
${ }^{4}$ Ruth Morrow, "Creative Activism: A Pedagogical and Research Tool," Enquiry: The ARCC Journal of Architectural Research 4, no. I (2007): 60-68; Harriet Harriss and Lynnette Widder, eds., Architecture Live Projects: Pedagogy Into Practice (New York: Routledge, 2014).
} 


\section{A series of interdisciplinary collaborations}

The two participatory design projects described, both included a full range of activities such as: extensive site visits varying in length from an afternoon to a full week; meetings and workshops; youth development projects; community funded University Summer Scholarships; and public exhibitions of the work undertaken.

Both exhibitions proved to be of particular success as they provided early opportunities for the groups to work together for a shared goal. The Tokelau public museum exhibition in Porirua and the Wairarapa community-based exhibition, held in a local community building, were well attended. What was unique for the Pataka Art + Museum was the high numbers of young attendees, many of whom were first time visitors. Other visitors to the "Tokelau: Then Now, Now Then" exhibition, which showed at the Pataka Art + Museum as part of the Wellington Arts Festival from 21 February to 13 April, 20I4, included Pasifika and Māori elders, church leaders, government officials, politicians and diplomats, as well as university leaders and students. The two exhibitions helped to strengthen the sense of community, preserve and showcase aspects of the culture and foster a collective shared vision for the future. Empowerment resulted from this grassroots participation, mutual decision-making and shared implementation and was evidenced by a wide range of 'spin-off activities, such as educational and family well-being initiatives. Figure 2 illustrates the relationship between the Pasifika Community, Victoria University of Wellington and Pataka Art + Museum.

We found that an interdisciplinary approach to design was important because it potentially led to greater sustainability outcomes but also it provided social benefits due to a more involved and socially inclusive design methodology ${ }^{10}$. Much architectural education emphasises individual and competitive learning " and it was therefore important that students had the chance to work with other disciplines such as interior architecture, museum studies, ecology, photography, and art curation on the complex problems that presented in group situations ${ }^{12}$. Building on prior student work enabled consistency, continuity of relationships and passing-on of knowledge and insights that are often difficult to achieve in long-term projects.

\footnotetext{
${ }^{5}$ Harriet Harriss and Lynnette Widder. Architecture Live Projects: Pedagogy into Practice / Edited by Harriet Harriss and Lynnette Widder. First ed. 2014.

${ }^{6}$ Donald A. Schon, The Reflective Practitioner: How Professionals Think in Action (New York: Basic Books, 1983); Edwina L. Stoll, "An Introduction to Collaborative Learning: From Theory to Application," Communication Education 45, n. 3 (1996): 260.

${ }^{7}$ Edwina L Stoll. "Collaborative Learning: Higher Education, Interdependence, and the Authority of Knowledge". Communication Education 45, n. 3 (1996): 260.

${ }^{8}$ Gregory S. Blimling, "Creating Contexts for Learning and Self-Authorship: Constructive Developmental Pedagogy (review)," The Journal of Higher Education 73, no. 2 (2002): 307; Robert Kegan, In Over Our Heads: The Mental Demands of Modern Life (Cambridge, MA: Harvard University Press, 1994).

${ }^{9}$ Robert Kegan. In over our heads: the mental demands of modern life / Robert Kegan. (Cambridge, Mass: Harvard University Press, 1994)

10 Daniel Christian Wahl and Seaton Baxter, "The Designer's Role in Facilitating Sustainable Solutions," Design Issues 24, n. 2 (2008): 72.

"Anthony D. Cortese, "The Critical Role of Higher Education in Creating a Sustainable Future," Planning for Higher Education 3I, n. 3 (2003): I5.

12 Maibritt Pedersen Zari, "Changes in Climate Driving Changes in Architectural Education," Enquiry: The ARCC Journal of Architectural Research 6, n. I (2009).
} 


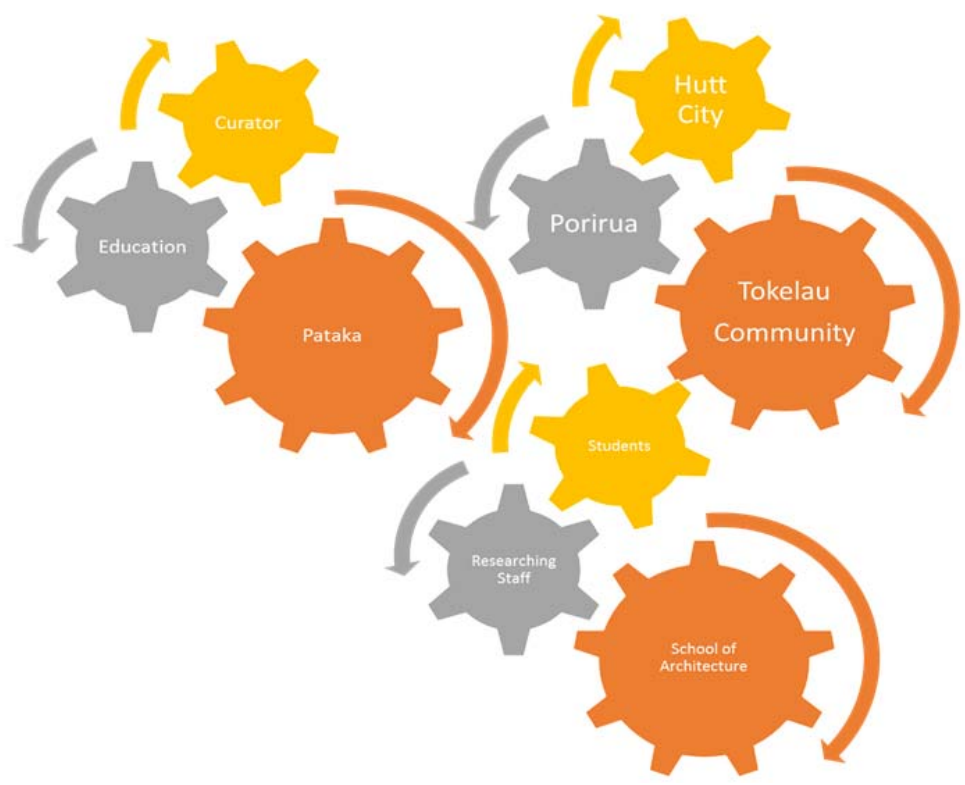

Figure 2: Diagram illustrating the relationship between the Tokelau Community, Victoria University of Wellington and Pataka Art + Museum.

\section{Participatory design}

Design-led philosophies and methods hinge on understanding that the health of a community has a symbiotic relationship with how empowered participants are engaged with their environment and can have a say in changing their existing condition into their preferred one. In our experience of participatory design methods, the roles of the designer and the researcher blur, and community becomes a critical component in the process $^{13}$. People involved want to express themselves and participate directly and proactively in the design development ${ }^{14}$. Both communities were excited to be involved in brainstorming, decision making and conceptual design of potential future scenarios. Participation in decisions that determine the quality and direction of built environments gives primacy to the community's rights to participate in the shaping of the world in which they live ${ }^{15}$. There is an ethical stand underlying participatory design that recognises an accountability of design to the world it creates and the lives of those who inhabit it. Participation hereby enhances the meeting of social needs while increasing the effective utilisation of resources at the disposal of a particular community ${ }^{16}$. For the two communities, it represented an increased sense of having influenced the decision-making process, and provided a greater awareness of the reasons for, and consequences of, the

\footnotetext{
${ }^{13}$ Elizabeth Sanders, "From User Centred to Participatory Design Approaches," in Design and Social Sciences: Making Connections, ed. Jorge Frascara (New York: Taylor \& Francis, 2002), 3.

${ }^{14}$ Elizabeth Sanders, "On Modeling: An Evolving Map of Design Practice and Design Research," Interactions 15, n. 6 (2008): 13.

${ }^{15}$ Henry Sanoff, Participatory Design: Theory \& Techniques (Raleigh, NC: Henry Sanoff distributor, 1990).

${ }^{16}$ City University of New York. Environmental Psychology Program. Working Group on Participation, and Lisa Cashdan, A Critical Framework for Participatory Approaches to Environmental Change (Center for Human Environments, 1978).
} 
decisions made. It also guaranteed more relevant and up-to-date information than previously available. Research has shown that the main source of user satisfaction is not so much the degree to which the individuals' needs are met, but the feeling that they have influenced the decision ${ }^{17}$. At different times in the process, both communities discussed the cultural shift from how it was no longer about hierarchies but about networks which led to stronger and more influential fronts. The collective became willing to express what they wanted, when they wanted it and how they wanted it. The challenge for the students was to explore an experiential design for the task at hand, one whose aim was to design the users' experiences of things, events and places. Creating this methodological framework enabled the effective use of rational design methods without affecting the creative processes ${ }^{18}$.

From on-going experiences grounded within both academic and professional practice, the authors acknowledge three critical stages where willing participants can contribute to the design process. These three critical stages are what we refer to as the base or the ABCs of design:
A) Design Analysis (holistic context);
B) Design Exploration and Testing (exploring design scenarios); and
C) Design Synthesis (agreed plan or direction).

\section{The role of the university in community based design-led research}

Prevailing discourse emphasises the university's place as a paramount player in a global system increasingly driven by knowledge, information, and ideas ${ }^{19}$. Knowledge has become a main driver of economic growth, and education is increasingly the foundation for individual prosperity and social mobility ${ }^{20}$. By focusing on the social, cultural, and cognitive bridges offered in specific courses of study, these types of community projects highlight the strengths of a multicultural, multidisciplinary, collaborative learning approach. A bridge must be anchored on both sides, with as much respect for where it begins as for where it ends ${ }^{21}$. Student activities have the ability to mediate between diverse worlds in the process of learning and exploring. On one side of the bridge lies the students' familiar home territory, including their family, work place, peers, and institutions ${ }^{22}$. On the other side is the territory of cultural communities, which are shaped by rules, traditions, discourse and values that may be very different from students' own understanding. The University can help students construct bonds between their own personal and cultural knowledge and that of another community and create pathways for them to learn

\footnotetext{
${ }^{17}$ Sanoff, Participatory Design.

18 Stefan K. Wrona, Participation in Architectural Design and Urban Planning (Poland: Warsaw Technical University, 1981).

${ }^{19}$ Stewart Clegg, Walter P. Jarvis and Tyrone S. Pitsis, "Making Strategy Matter: Social Theory, Knowledge Interests and Business Education," Business History, 55, n. 7 (20।3).

${ }^{20}$ Robert Lawy and Gert Biesta, "Citizenship as Practice: The Educational Implications of an Inclusive and Relational Understanding of Citizenship,” British Journal of Educational Studies 54 (2006): 34.

${ }^{21}$ Kegan, In Over Our Heads.

${ }^{22}$ Richard Beach, Dana Britt Lundell, and Hyang-Jin Jung, "Developmental College Students' Negotiation of Social Practices Between Peer, Family, Workplace, and University Worlds," in Exploring Urban Literacy \& Developmental Education, ed. Dana Britt Lundell and Jeanne L. Higbee (Minneapolis: Center for Research on Developmental Education and Urban Literacy, University of Minnesota, 2002), 79.
} 
from the communities' experiences and ways of knowing and being. For example, in the Tokelau project, students from different courses, different years of study and different design disciplines formed a learning community in which members helped each other learn to research a wide range of topics, from sustainable energy solutions, through lowcost furniture construction to community centre planning and design. By building upon prior student work and through supporting each other by listening, problem-solving, and working together, students honed academic skills and explored ideas in ways that valued individual knowledge. In the case of the Wairarapa regeneration project, students studied local ecologies, traditional practices and cultural ways of knowing. In both cases, students were invited to use academic skills to explore what it means to practice community: by working together as a group with a shared mission in order to better understand the nature of design-led research.

Facilitation and coordination practices continued beyond the design itself into actual implementation of the projects. Tokelauan youth built stylish no-cost furniture from found materials working from student designs, then advanced this strategy into the construction of an outdoor cooking and eating area as well as implementing a new form of community centre planning. The Wairarapa community used the regeneration project to inform their youth of traditional indigenous practices. This assisted both communities in finalising their development plans and led to a sustainable result that engendered a strong sense of ownership. The process also built upon skills that the community already had, such as detailed construction and cultural techniques which reinforced their own design languages and cultural understandings.

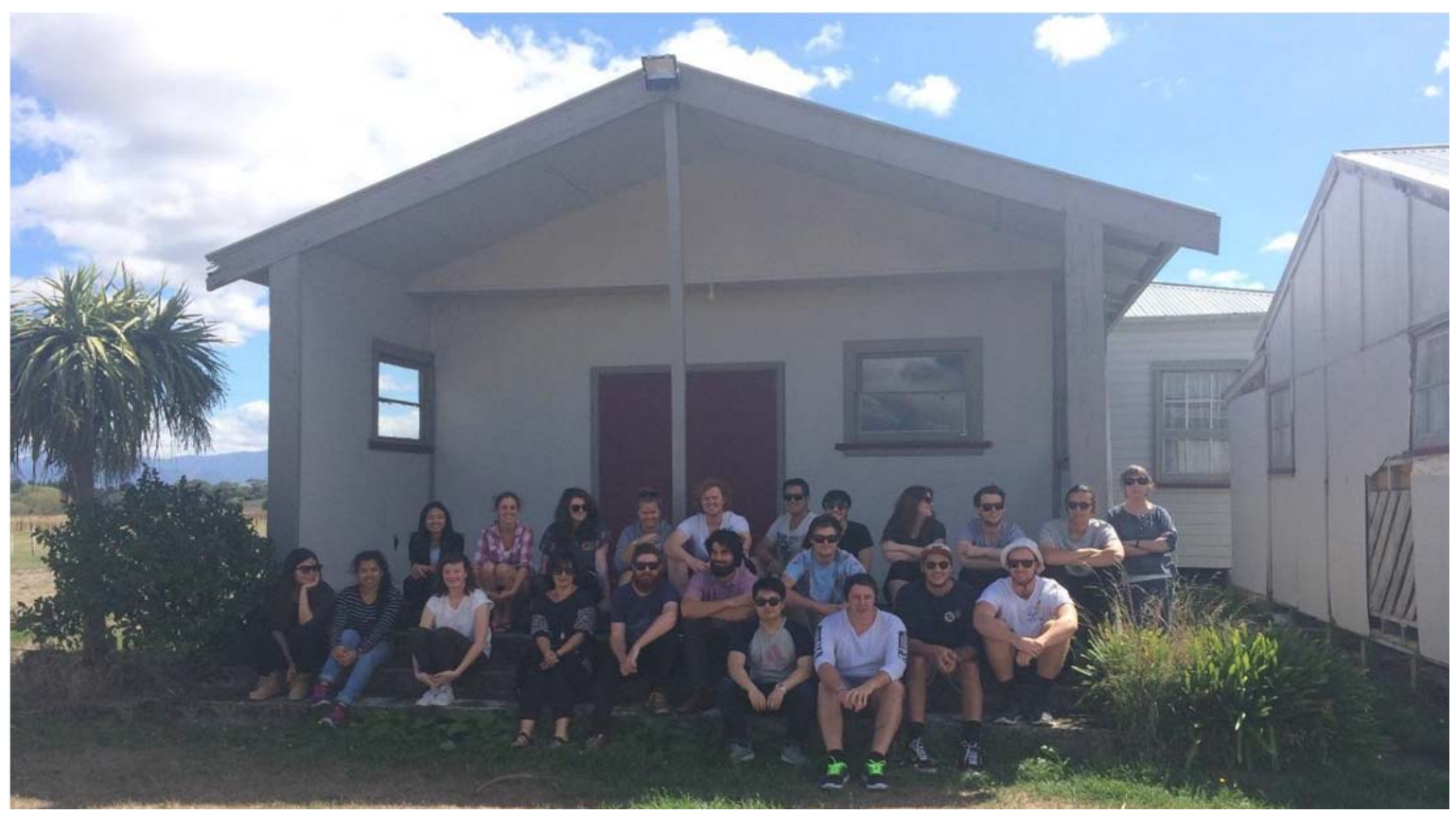

Figure 3: Akoranga Wairarapa Moana project: students outside Hurunui-o-Rangi marae in the Wairarapa.

Facilitation and coordination practices continued beyond the design itself into actual implementation of the projects. Tokelauan youth built stylish no-cost furniture from found materials working from student designs, then advanced this strategy into the 
construction of an outdoor cooking and eating area as well as implementing a new form of community centre planning. The Wairarapa community used the regeneration project to inform their youth of traditional indigenous practices. This assisted both communities in finalising their development plans and led to a sustainable result that engendered a strong sense of ownership. The process also built upon skills that the community already had, such as detailed construction and cultural techniques that reinforced their own design languages and cultural understandings. It transformed from the "designer's project" to the community's project.

\section{Conclusion}

This paper explores the motivation for design-led research with a collaborative, interdisciplinary and participatory mind-set. Research involving Māori and Pasifika cultures can benefit from alternative design strategies that are not entirely based on an abstract set of universal design principles but extend and expand from these principles in a way derived from their own specific cultural contexts. The process "....is more than a technical process; it requires the active participation of community members. Through their participation, they validate their culture, keeping it alive and evolving"23.

Experiences has found that many community development 'experts', be they practicing in policy, planning, design or all mentioned, still undertake a conventional design approach which may include: a shallow analysis, a possible survey of client requirements and expectations and a 'for information only' level of public consultation - often only informing certain members of the public about the already-agreed-on design direction. These preliminary actions are then followed by desktop design preparation. A plan and/or report is produced to be either shelved or used at the local authority's discretion. Ultimately, in this way, the design process can be played out literally behind closed doors. End users may awaken one day to be greeted by the latest new amenity or development to be imposed on their community.

In the production of an exhibition with hybrid 'collectives' of academics, laypersons, community members, artefacts and activities, there is the creation of a new network and a reconfiguration of the boundaries between research knowledge and new forms of design practice. Design institutions can mediate between cultures and foster social change through the education of their students as world citizens and applied researchers.

There are many benefits to this design-led approach, as evidenced by the outcomes from the Pataka, Art + Museum exhibition, including improving civic participation and ensuring more democratic results. Similarly as demonstrated by the Māori community engagement, this approach can create a strong sense of community, strengthening people's attachment to their place and to each other, as well as producing more sustainable solutions. Conceptualising student learning as a dynamic process of interaction between communities, histories, and contexts, replaces the view that equates agency with individual self-sufficiency. Themes of identity, community, and agency arose from the work and instead of being isolated by difference, students were proposing that

\footnotetext{
${ }^{23}$ Michael Hibbard. \& Adkins, Robert. 'Culture and Economy: The Cruel Choice Revisited', in Ryan Walker, David Natcher, and Ted Jolola, (eds.), Reclaiming Indigenous Planning, (Montreal: McGill-Queen's University Press, 2013), 72.
} 
communities embrace interdependence. Agency is viewed as a matter of participation, collaboration, and a shared sense of mission.

The diverse activities discussed in this paper gave students multiple opportunities to articulate their own understandings of culture in the framework of developing sensitive, sustainable design-led solutions. By constructing their own ways to integrate personal and cultural knowledge with the course content, students acted as creators of knowledge and partners with instructors rather than as passive consumers. There was often a heightened sense of vulnerability and uncertainty that was both exhilarating and problematic. However, for most students the community provided an anchor and a kind of accountability they might not have experienced if they were in a course without community connection. In this manner, interdisciplinary and design-led research can provide an essential interface between teaching and practice. 